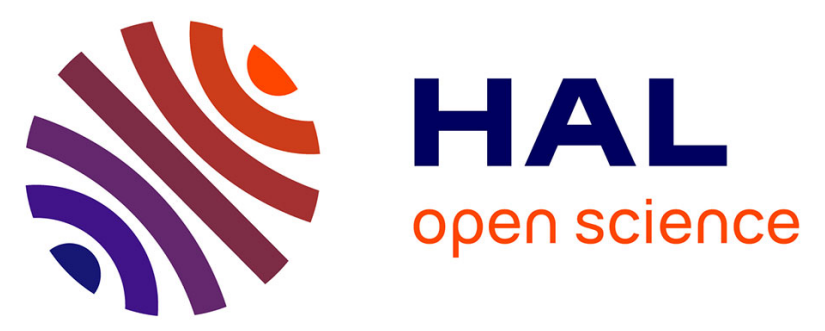

\title{
Large bolometer arrays with superconducting NbSi sensors for future space experiments
}

F. Pajot, Y. Atik, C. Evesque, S. Lefranc, B. Leriche, J.-P. Torre, B. Belier, N. Marsot, L. Dumoulin, L. Berge, et al.

\section{- To cite this version:}

F. Pajot, Y. Atik, C. Evesque, S. Lefranc, B. Leriche, et al.. Large bolometer arrays with superconducting NbSi sensors for future space experiments. 12th International Workshop on Low Temperature Detectors - LTD-12, Jul 2007, Paris, France. Springer, 151, pp.513-517, 2008, 10.1007/s10909-0079680-7 . in2p3-00196874

\section{HAL Id: in2p3-00196874 https://hal.in2p3.fr/in2p3-00196874}

Submitted on 18 Dec 2007

HAL is a multi-disciplinary open access archive for the deposit and dissemination of scientific research documents, whether they are published or not. The documents may come from teaching and research institutions in France or abroad, or from public or private research centers.
L'archive ouverte pluridisciplinaire HAL, est destinée au dépôt et à la diffusion de documents scientifiques de niveau recherche, publiés ou non, émanant des établissements d'enseignement et de recherche français ou étrangers, des laboratoires publics ou privés. 


\title{
Large bolometer arrays with superconducting NbSi sensors for future space experiments
}

\author{
F. Pajot ${ }^{1}$, Y. Atik ${ }^{1}$, C. Evesque ${ }^{1}$, S. Lefranc ${ }^{1}$, B. Leriche ${ }^{1}$, J-P. \\ Torre $^{1}$, B. Bélier ${ }^{2}$, N. Marsot $^{2}$, L. Dumoulin ${ }^{3}$, L. Bergé ${ }^{3}$, M. Piat ${ }^{4}$, \\ E Bréelle ${ }^{4}$, D Prêle ${ }^{5}$, A. Benoit ${ }^{6}$, C. Hoffmann ${ }^{6}$, T. Durand ${ }^{6}$, \\ P. Camus ${ }^{6}$, D. Santos ${ }^{7}$, Yong Jin ${ }^{8}$, M Giard ${ }^{9}$ \\ Received July 23, 2007, Accepted October 5, 2007 \\ ${ }^{1}$ CNRS-IAS Bât. 121, Université Paris Sud-11, F- 91405 Orsay, France \\ ${ }^{2}$ CNRS-IEF Bât. 220, Université Paris Sud-11, F- 91405 Orsay, France \\ ${ }^{3}$ CNRS-CSNSM Bât 104, Université Paris Sud-11, F- 91405 Orsay, France \\ ${ }^{4}$ CNRS-APC 10 rue A. Domon et L. Duquet, 75205 Paris cedex 13, France \\ ${ }^{5}$ CNRS-LISIF 3 rue Galilée Site "Saint Raphael", F-94200 Ivry sur Seine \\ ${ }^{6}$ CNRS-Institut Neel 25 avenue des Martyrs, F-38042 Grenoble, France \\ ${ }^{7}$ CNRS-LPSC 53 avenue des Martyrs, F-38026 Grenoble, France \\ ${ }^{8}$ CNRS-LPN Site Alcatel, Route de Nozay, F-91460 Marcoussis, France \\ ${ }^{9}$ CNRS-CESR 9 avenue du Colonel Roche, F-31028 Toulouse, France
}

Email : francois.pajot@ias.u-psud.fr

New techniques in microelectronics allow to build large arrays of bolometers filling the focal plane of submillimeter and millimeter telescopes. The expected sensitivity increase is the key for the next generation of space experiments in this wavelength range. Superconducting bolometers offer currently the best prospects in terms of sensitivity and multiplexed readout. We present here the developments led in France based on NbSi alloy thermometers. The manufacturing process of a 23 pixel array and the test setup are described.

\section{INTRODUCTION}

The design of current space missions dedicated to submillimeter and millimeter broadband or low spectral resolution observations is based on direct detectors limited by the photon noise of the incoming radiation in a 
diffraction limited beam. Bolometers are the most sensitive detectors for this purpose. They are associated to feedhorns and arranged in groups covering a fraction only of the focal plane area. It is the case in the HFI/Planck and SPIRE/Herschel instruments.

The study of the inflation phase of the universe requires large improvements of sensitivity in the measurement of the Cosmic Microwave Background polarized emission. The ESA Cosmic Vision and NASA Beyond Einstein programs includes such missions.

An increase factor of 10 to 100 is required in sensitivity with respect to current missions. This cannot be obtained by increasing the integration time, already counted in years for a whole sky survey. The only solution is a full coverage of the focal plane by large contiguous detector arrays of 10000 pixels or more.

We present here a french collaborative effort in the development of such arrays. The DCMB (Développement Concerté de Matrices de Bolomètres) R\&D program is supported by CNES (Centre National d'Etudes Spatiales), the CNRS (Centre National de la Recherche Scientifique) and the participating Universities. The subsystems concerned by the R\&D program are: the thermal architectures of the bolometers arrays, the thermometers, the coupling with the optical radiation and the readout electronics (1). Two types of thermometers are being studied, based on Niobium Silicon alloys: high impedance (Anderson isolator) or superconducting alloys. We will develop here the superconducting case ( $\mathrm{Nb}$ fraction larger than 0.13). Superconducting bolometers technology provides sensitive detectors (below $10^{-17} \mathrm{WHz}^{-1 / 2}$ ) and allows the use of a convenient multiplexed readout based on SQUIDs (2).

\section{ARRAYS MANUFACTURING}

The thermal architecture (figure 1) and thermometers are developped in common for both types of thermometers in the microelectronics facility IEF/MINERVE of Paris Sud-11 University at Orsay. $\mathrm{Nb}$ and $\mathrm{NbSi}$ are deposited in dedicated evaporators and co-evaporators of CSNSM/Orsay.

\subsection{Thermometers}

The thermometric sensor (figure 2) is composed of a film of $\mathrm{NbSi}$ (Niobium Silicon) $100 \mathrm{~nm}$ thick. It is co-evaporated by irradiating two targets of $\mathrm{Nb}$ and $\mathrm{Si}$ simultaneously. The mixing ratio $x$ of the $\mathrm{Nb}_{\mathrm{x}} \mathrm{Si}_{\mathrm{x}-1}$ thermometer is adjusted in order to obtain the goal transition temperature (3). In order to lower (below $1 \Omega$ ) the average resistance at the superconducting transition, an interleaved comb geometry is used. 


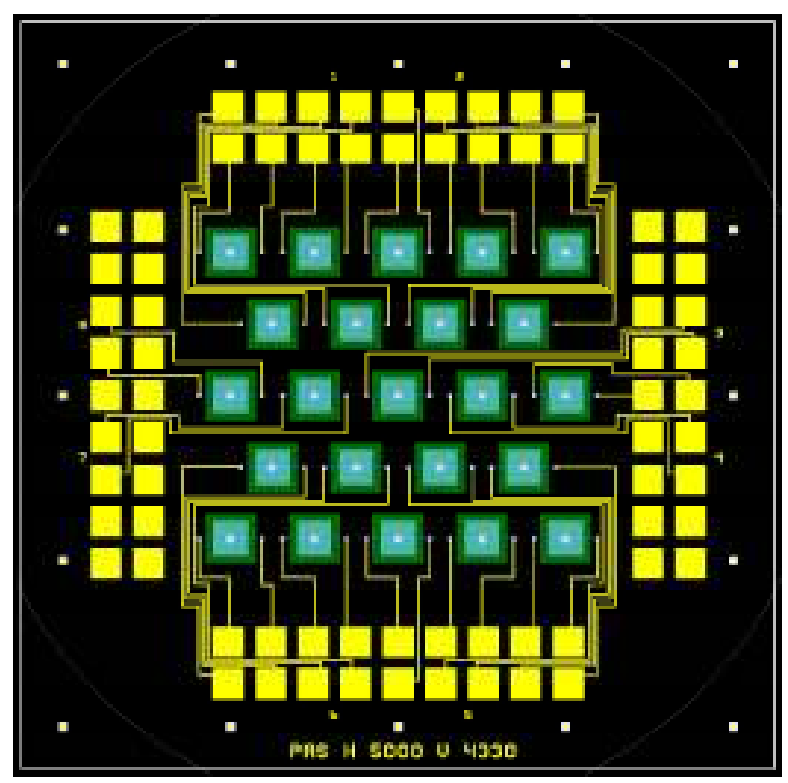

Fig. 1(color online) 23 pixels array architecture

The superconducting thermometer is voltage biased at the normalsuperconducting transition. This transition is very steep, so the total power and consequently the temperature remains quasi-constant when the input radiation varies. This effect is the well know "strong negative electro-thermal feedback" (4) (5). This negative feedback also strongly decreases the time constant of the system. A typical NbSi thermometer $(10 \mathrm{~mm} \times 10 \mathrm{~mm})$ transition curve was previously measured (6). The design is scaled down to $0.8 \mathrm{~mm} \times 0.8 \mathrm{~mm}$ for the 23 pixels array.

\subsection{Contact pads}

A metal layer is deposited to make the electric interface between the tracks and the contacts. Gold offers the advantage of a compatibility with niobium connections and also a good aptitude for connections with the external readout system. A layer of gold $(1000 \AA-1500 \AA)$ is thus deposited on the ends of the $\mathrm{Nb}$ tracks. 


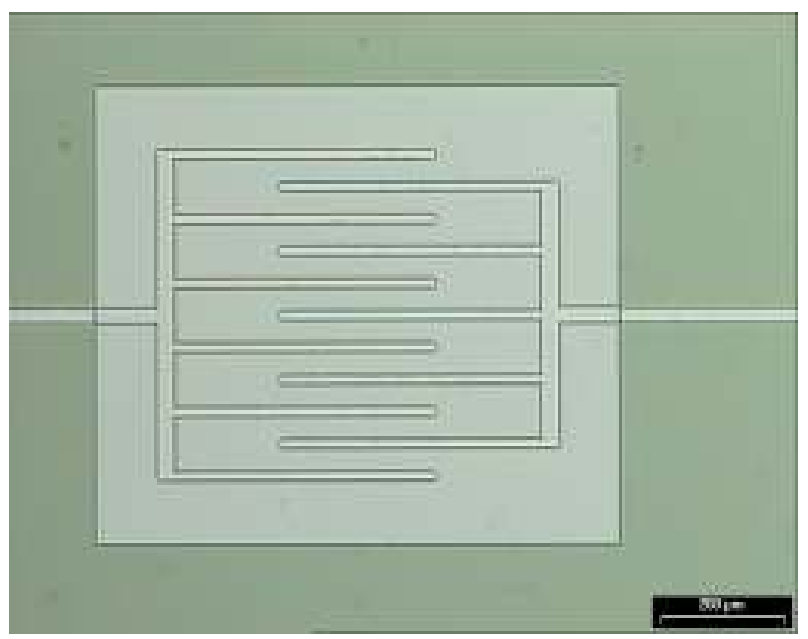

Fig. 2: (color online)NbSi superconducting thermometer. The leads comb structure is $\mathrm{Nb}$, and the square $\mathrm{NbSi}$.

\subsection{Microfabrication process}

The steps of microfabrication of the superconducting bolometers are as follows:

1. Deposition of membranes material by PECVD $\left(\mathrm{SiO}_{2}+\mathrm{Si}_{3} \mathrm{~N}_{4}\right.$ : $\mathrm{SiO} 2 / \mathrm{SiN} / \mathrm{SiO} 2=290 / 230 / 100 \mathrm{~nm})$

2. $\mathrm{Nb}_{\mathrm{x}} \mathrm{Si}_{1-\mathrm{x}}$ co-evaporation $(\mathrm{x}=15.55 \%, 1000 \AA)$

3. $\mathrm{Nb}$ evaporation $(500 \AA)$

4. Au evaporation

5. Silicon deep etching

\section{$1.4 \quad$ Readout}

Multiplexed readout will be performed using a $4 \mathrm{~K}$ SiGe ASIC associated with SQUIDs. Development of the ASIC is described by D. Prele et al. (this conférence). SQUIDs mux and amplifiers procurement is currently in discussion with Supracon (Jena).

\subsection{Coupling with radiation}

For the first realisation, the radiation will be absorbed by a standard resistive layer or a grid adapted to the vacuum impedance. The long term goal is to couple to the incoming radiation by means of antenna (7). 


\section{ARRAYS TEST AND CHARACTERISATION}

$\mathrm{NbSi}$ alloy is a new material for TES design. It requires a full characterisation and validation before using it to produce large arrays. The uniformity of the superconducting transition temperature and slope is being checked on a 23 pixels array for which only the thermometers are built (figure 3). The test bench, based on a $300 \mathrm{mK}$ mini-fridge system, is being developped at IAS. In parallel, a second bench is being set up to characterize the noise properties of a single $\mathrm{NbSi}$ superconducting thermometer. It is based on a commercial SQUID system from Star Cryoelectronics, and a $300 \mathrm{mK}$ mini-fridge and a thermal stage regulated between 300 and $500 \mathrm{mK}$. Measurements are under way.

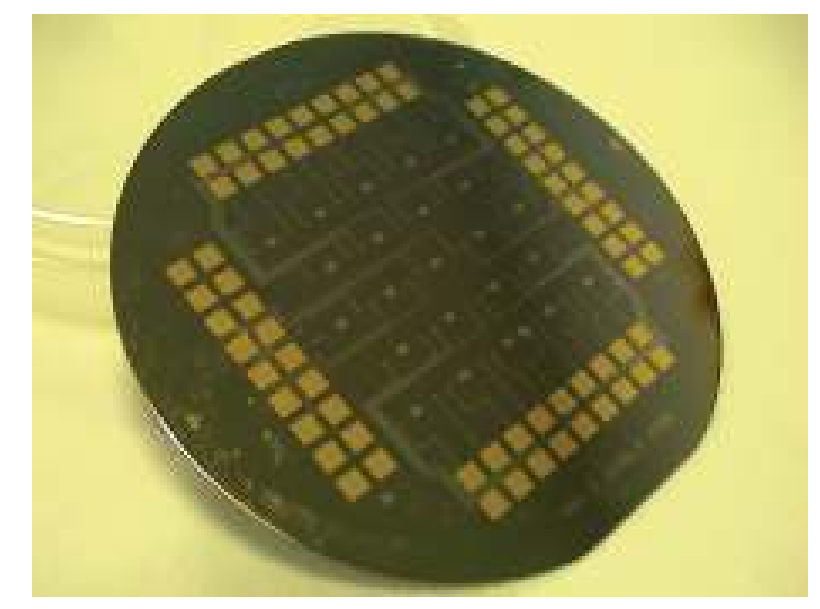

Fig. 3: (color online)23 pixels thermometers only array

\section{CONCLUSION}

The process required to build the thermometer array have been set up. The testing phase can now begin, for a single pixel for noise measurement on one side, and for a 23-pixels array for thermometer homogeneity measurement on the other side. Once this phase is passed, we will be able to continue the integration of a complete array with optical coupling. 


\section{REFERENCES}

1. Camus Ph. et al, "Low temperature NbSi thin film bolometers on Silicon Nitride membranes low temperature for bolometer applications", NIMA A 444 (2000) pp. 419-422.

2. J.G. Staguhn, D.J. Benford et al., "Astronomical demonstration of superconducting bolometer arrays", 2003, Proc. SPIE 4855 (2003), pp 100-107.

3. M. Ukibe et al., "Fabrication of large NbSi bolometer arrays for CMB applications", Nuclear instruments \& Method in physics research 559 (2006) pp 554-556.

4. A. T. Lee, P. L. Richards, S. W. Nam, B. Cabrera and K.D. Irwin, A superconducting bolometer with strong electrothermal feedback. Appl. Phys. Lett. 69, 1801 (1996).

5. J.M. Gildemeister, "Voltage-Biased Superconducting Bolometers for Infrared and mm-Waves ", doctoral dissertation, UC Berkeley (2000).

6. S. Lefranc et al., "Superconducting NbSi thermometers for use in TES devices", Nuclear instruments \& Method in physics research 559 (2006) pp 468-470.

7. C.L. Kuo, J.J. Bock et al., Antenna-coupled TES bolometers for CMB polarimetry, Proc. SPIE 6275 (2006), p 1 